\title{
DESEMPENHO DE ARGAMASSAS DE REVESTIMENTO PRODUZIDAS COM BORRACHA DE PNEUS
}

\section{PERFORMANCE COATING MORTARS PRODUCED WITH RUBBER TIRES}

\author{
Nayra Alberici Pinto, Mestranda (FEIS/UNESP) \\ Cesar Fabiano Fioriti, Doutor (FCT/UNESP)
}

\author{
Palavras Chave \\ Resíduos de borracha; Material alternativo; Desempenho
}

\section{Key Words}

Rubber tires; Alternative material; Performance

\section{RESUMO}

Este trabalho teve como objetivo estudar argamassas mistas de revestimento produzidas com $10 \%$ em volume de resíduos de borracha de pneus, em substituição parcial ao agregado miúdo, aplicadas em painéis de alvenaria. Foi analisado o desempenho das argamassas de revestimento mediante a realização de ensaios de permeabilidade à água, resistência ao impacto de corpo duro e susceptibilidade à fendilhação. As granulometrias de borracha utilizadas foram denominadas de fina $(\# 0,075 \mathrm{~mm})$ e grossa $(\# 2,38 \mathrm{~mm})$. Os resultados indicaram nas argamassas produzidas com borracha: tendência de maior permeabilidade à água com o aumento da granulometria da borracha; que a maior granulometria apresenta o melhor resultado de impacto de corpo duro; e que não ficam sujeitas a ocorrência de fissuras. Diante disso, teve-se como indicativo de melhor resultado a granulometria de borracha fina.

\section{ABSTRACT}

This work aimed to study mixed coating mortars produced with $10 \%$ by volume of residues tires rubber in partial replacement to aggregate kid, applied in masonry panels. Was analyzed the behavior of coating mortars by conducting tests of permeability to water, impact resistance hard-body and susceptibility to cracking. The different sizes of rubber used were called thin (\#0.075 $\mathrm{mm}$ ) and thick (\# $2.38 \mathrm{~mm}$ ). The results indicated in the mortars produced with rubber: trend of greater permeability to water with increasing particle size of rubber; the largest rubber size presented the best result hard-body impact; and that are not subject to the occurrence of cracks. Given this, as indicative of better result the size of thin rubber. 


\section{INTRODUÇÃO}

A recente discussão do problema ambiental causado pelos resíduos é uma demonstração da necessidade de metodologia de pesquisa e desenvolvimento que inclua os aspectos ambientais. Pois a questão ambiental vem sendo amplamente discutida a nível nacional e internacional nos últimos anos, tendo mobilizado a opinião pública e assumindo um papel preponderante nas comunidades.

De maneira paralela é importante que sejam desenvolvidas técnicas construtivas que diminuam o volume de resíduos de pneus gerados atualmente. De fato, a utilização deste material para a produção de argamassas pode ser uma das alternativas para o problema dos resíduos de pneus. Ainda mais no Brasil, onde há a tradição de se executar os revestimentos em argamassa.

Estudos sobre a produção de argamassas com borracha de pneus demonstram a possibilidade de este material substituir, parcialmente, agregados de origem natural, contribuindo para o meio ambiente em função de utilizar um resíduo poluente e substituí-lo por materiais de fontes naturais finitas. Foram observadas, no entanto, modificações do comportamento das argamassas nos estados fresco e endurecido, em relação às argamassas sem incorporação de borracha de pneus.

De maneira geral, os resultados mostram que a produção de argamassas com borracha de pneus implica em uma diminuição significativa na densidade de massa aparente no estado fresco e no estado endurecido, na resistência à compressão e na resistência à tração por flexão (PEDRO, 2011; TRIGO et al., 2005).

No entanto, verifica-se uma descida do módulo de elasticidade e um melhor desempenho na resistência ao impacto de corpo duro. Desta forma, e visto que em argamassas de revestimento a resistência não é uma prioridade acima de determinados níveis, este comportamento (ductilidade melhorada) é uma característica que melhora a durabilidade do material (RAGHVAN et al., 1998; PEDRO, 2011).

Dessa forma, o objetivo deste trabalho foi avaliar o desempenho de argamassas de revestimento produzidas com duas diferentes granulometrias de borracha de pneus, por meio de ensaios de permeabilidade à água, resistência ao impacto de corpo duro e susceptibilidade à fendilhação.

\section{MATERIAIS E MÉTODOS}

\subsection{Materiais}

Os materiais utilizados na composição das argamassas mistas foram o cimento CP II F-32, cal CH-III, areia natural e a borracha de pneus. Com a finalidade de caracterizá-los, foram determinadas as densidades de massa aparente dos materiais: cimento e cal - ambas pela NBR NM 23 (ABNT, 2011), areia e borracha de pneus - ambas pela NBR NM 45 (ABNT, 2006). Posteriormente foram determinadas suas densidades de massa absoluta: cimento e cal ambas pela NBR NM 23 (ABNT, 2011), areia - NBR NM 52 (ABNT, 2009) e a borracha de pneus - NBR NM 53 (ABNT, 2003), conforme apresenta a Tabela 1.

Tabela 1: Resultados de densidade de massa dos materiais.

\begin{tabular}{|c|c|c|}
\hline \multirow{2}{*}{ Material } & \multicolumn{2}{|c|}{$\begin{array}{c}\text { Densidade de massa } \\
\left(\mathrm{g} / \mathrm{cm}^{3}\right)\end{array}$} \\
\cline { 2 - 3 } & Aparente & Absoluta \\
\hline Cimento & 1,450 & 3,080 \\
\hline Cal & 0,689 & 2,393 \\
\hline Areia & 1,509 & 2,617 \\
\hline Borracha & 0,320 & 1,150 \\
\hline
\end{tabular}

As duas granulometrias de borracha utilizadas foram obtidas através do processo mecânico de recauchutagem de pneus de caminhões. Tais resíduos possuem uma composição bastante diversificada em relação as suas dimensões, e sua separação no local de beneficiamento é uma prática impossível. Sendo assim, optou-se por executar a seleção por processo de peneiramento em laboratório.

Durante o beneficiamento da amostra de borracha de pneus foram descartados o aço e o nylon, ou quaisquer outras impurezas que pudessem afetar o desempenho das argamassas produzidas de forma mais significativa. O total de aproveitamento dos resíduos de borracha de pneus coletados foi de $80 \%$. Assim, o $20 \%$ de material restante ficou constituído de pedaços grandes da banda de rodagem dos pneus, ficando excluídos deste estudo. A seguir, a descrição da borracha de pneus que foi utilizada: Figura 1: a) Borracha fina; b) Borracha grossa

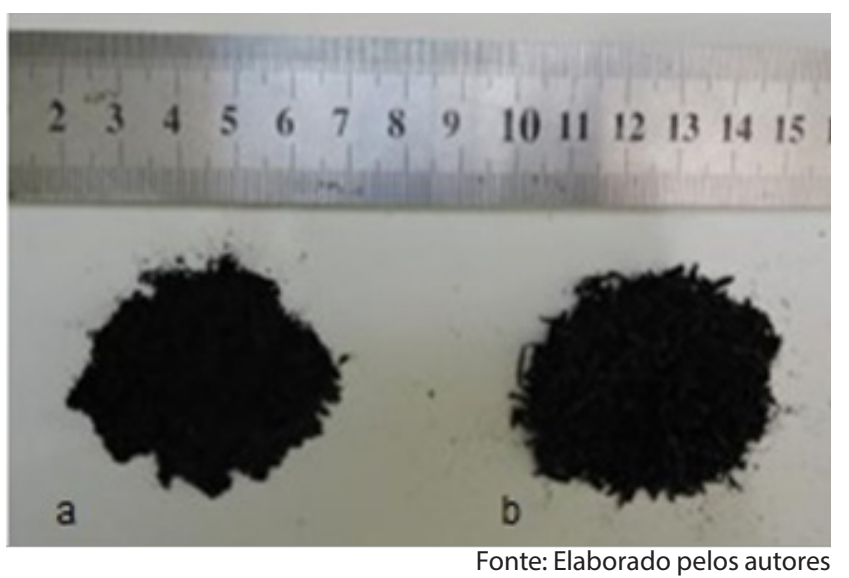

- borracha fina: apresenta forma granular (tipo pó), passante na peneira $\# 0,075 \mathrm{~mm}$, Figura 1a; 
- borracha grossa: também com forma alongada (tipo fibra), apresenta comprimentos máximos por volta de $10 \mathrm{~mm}$, passante na peneira $\# 2,38 \mathrm{~mm}$, Figura $1 \mathrm{~b}$.

\subsection{Produção dos painéis}

Foram confeccionados um total de 8 painéis de alvenaria com dimensões de $50 \mathrm{~cm} \times 50 \mathrm{~cm}$, sendo que primeiramente foram feitos os moldes em madeira para facilitar a execução dos painéis. Posterior a isso, aplicou-se duas demãos de verniz marítimo (Figura 2a), impermeabilizando-os, isso foi realizado com o objetivo de se evitar que a madeira absorvesse a água da argamassa de assentamento.

Depois da secagem do verniz nos moldes foram fabricados os painéis de alvenaria, isso foi realizado diante da colocação de tijolos comuns (cuja matéria prima é argila misturada com um pouco de solo arenoso), possuindo dimensões de: $10,20 \mathrm{~cm} \times 5,20 \mathrm{~cm} \times 22,20 \mathrm{~cm}$, na posição espelhada, com argamassa de assentamento de traço 1: 1: 3 (cimento, cal e areia), adotada segundo THOMAZ (2001), com a junta de argamassa de assentamento sendo de aproximadamente $1 \mathrm{~cm}$. Finalizando essa etapa, os painéis de alvenaria receberam o chapisco (Figura $2 b$ ) de traço 1: 3 (cimento e areia), adotado também conforme THOMAZ (2001), para que ocorresse posteriormente, maior aderência da argamassa de revestimento.

Figura 2: a) Detalhe de molde de madeira; b) Total de 8 painéis com aplicação de chapisco.

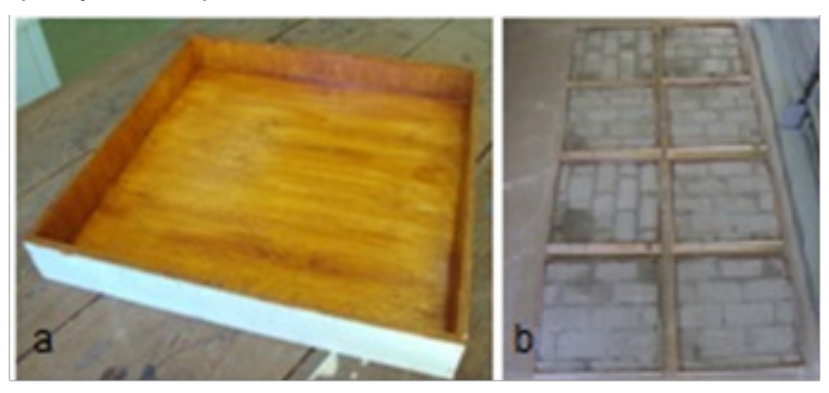

Fonte: Elaborado pelos autores

\subsection{Composição dos traços}

Foi adotado neste trabalho o traço em volume de materiais secos (cimento, cal e areia) 1: 1: 5, conforme THOMAZ (2001), com substituição parcial de 10\% em volume do agregado miúdo por borracha de pneus. $O$ teor de borracha de pneus utilizado representa uma quantidade significativa, considerando-se que a massa específica da borracha é baixa. Além disso, levando-se em consideração resultados obtidos nas referências PEDRO (2011), TRIGO et al. (2005), FIORITI (2007), os mesmos sempre utilizaram teores de borracha que variaram de $3 \%$ a $20 \%$ em volume, em suas composições cimentícias.
Inicialmente foi feita a transformação dos traços em volume para massa, onde os proporcionamentos dos materiais, em massa, foram definidos a partir dos resultados da densidade de massa do cimento, da cal, da areia e da borracha de pneus.

O plano experimental incluiu a execução de 4 traços de argamassas, sendo 3 com utilização de borracha de pneus e 1 sem a utilização de borracha (controle - parâmetro de comparação). A espessura da argamassa de revestimento aplicada nos painéis de alvenaria foi de $1,5 \mathrm{~cm}$.

A borracha de pneus foi separada em faixas granulométricas bem definidas, apresentando inclusive uma fácil distinção visual. $O$ intuito das diferentes granulometrias foi observar sua influência no comportamento das argamassas de revestimento.

As Tabelas $2 \mathrm{e} 3$ apresentam o quantitativo dos materiais utilizados em cada traço de argamassa produzido em laboratório.

Tabela 2: Quantidade de materiais utilizados no traço da argamassa controle.

\begin{tabular}{|c|c|c|}
\hline Materiais & $\mathrm{kg} / \mathrm{m}^{\mathbf{3}}$ & $\%$ Volume \\
\hline Cimento & 283,89 & 9,22 \\
\hline Areia & 1487,16 & 56,83 \\
\hline Cal & 133,21 & 5,57 \\
\hline Borracha & 0,00 & 0,00 \\
\hline Água & 283,89 & 28,39 \\
\hline$\Sigma$ & 2188,15 & 100,00 \\
\hline
\end{tabular}

Fonte: Elaborado pelos autores

Tabela 3: Quantidade de materiais utilizados no traço das argamassas com borracha de pneus.

\begin{tabular}{|c|c|c|}
\hline Materiais & $\mathbf{k g} / \mathbf{m}^{\mathbf{3}}$ & \% Volume \\
\hline Cimento & 283,89 & 11,73 \\
\hline Areia & 1251,63 & 49,68 \\
\hline Cal & 133,21 & 11,57 \\
\hline Borracha & 53,42 & 10,00 \\
\hline Água & 283,89 & 17,01 \\
\hline$\Sigma$ & 2006,04 & 100,00 \\
\hline
\end{tabular}

Fonte: Elaborado pelos autores

\subsection{Ensaios do programa experimental}

\subsubsection{Permeabilidade à água}

Nestes ensaios fez-se a opção pelo Método do Cachimbo (CSTC, 1982). O ensaio de permeabilidade à água foi realizado nas idades de 7, 28 e 56 dias, com a utilização de um painel por traço de argamassa produzida. Foi utilizado como resultado final a média aritmética apresentada pela fixação de 2 cachimbos (Figura 3) em cada painel estudado. 
Figura 3: a) Painéis revestidos com argamassa; b) Cachimbo fixado na argamassa.

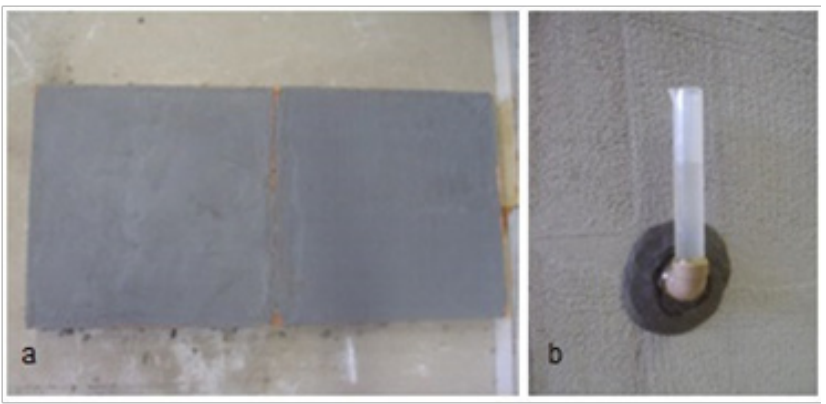

Fonte: Elaborado pelos autores

\subsubsection{Resistência ao impacto de corpo duro}

Para a avaliação dessa propriedade foi utilizado uma adaptação de dois métodos CSTB (1993) e a extinta NBR 9454 (ABNT, 1986). Os ensaios de resistência ao impacto de corpo duro foram realizados aos 28 dias de idade, utilizando um painel por traço de argamassa produzido. $\mathrm{O}$ aparato utilizado na realização dos ensaios esta apresentado na Figura 4.

Figura 4: Aparato utilizado no ensaio de impacto de corpo duro.

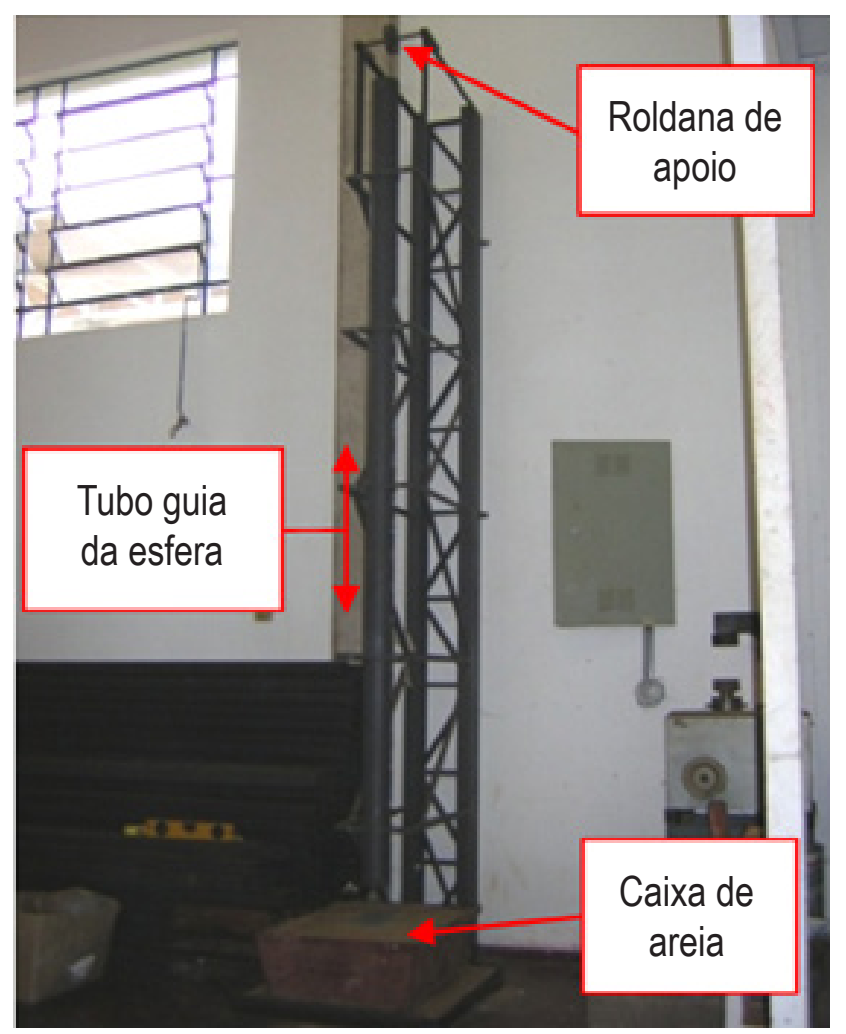

Fonte: Elaborado pelos autores

\subsubsection{Susceptibilidade à fendilhação}

O ensaio de susceptibilidade à fendilhação não segue nenhuma norma ou especificação. Este ensaio consiste em efetuar uma observação visual à argamassa de revestimento aplicada no painel, ao longo do tempo, de modo a detectar a existência de fissuras.
Este ensaio ocorreu nas idades de 7, 28 e 56 dias, em cada painel produzido por traço de argamassa.

\section{RESULTADOS E DISCUSSÃO}

\subsection{Permeabilidade à água}

A permeabilidade à água é uma propriedade dos revestimentos relacionada com a absorção capilar da estrutura porosa e eventualmente fissurada da camada de argamassa endurecida. A permeabilidade desta camada tem fundamental importância na determinação da estanqueidade do sistema vedação, e no nível de proteção que o revestimento deve oferecer a base contra a ação das chuvas ou de águas de lavagem da edificação. Na sequência serão apresentados os resultados dos ensaios de permeabilidade através da Figura 5.

Pelos resultados da Figura 5 percebe-se que o aumento da granulometria de borracha de pneus incorporada na argamassa apresenta uma tendência de absorver mais água, consequentemente sendo mais permeável.

Podemos notar que a argamassa produzida com a borracha fina $(0,22 \mathrm{ml} / \mathrm{min})$ apresentou os melhores resultados de taxa média de absorção de água em relação à argamassa controle $(0,15 \mathrm{ml} / \mathrm{min})$.

Visualmente se observou uma diferenciação do aspecto quanto à rugosidade das argamassas de revestimento produzidas, sendo que a argamassa controle ficou com um aspecto mais liso enquanto a argamassa com incorporação de borracha grossa apresentou aspecto final mais rugoso, o que de certa forma pode ter contribuído em uma maior absorção da água. Isso se explica pelo fato de a borracha ser um material que, possivelmente, não preenche todos os vazios produzidos pelo compósito, deixando assim um material mais permeável.

Segundo TRIGO et al. (2005), que analisaram diferentes granulometrias de borracha de pneus no concreto, os mesmos concluíram que a capacidade de absorção de água sofreu interferência com as dimensões das partículas de borracha, pois para as granulometrias mais finas a absorção de água foi menor.

Foi observado por este trabalho que o uso de borracha de pneus altera a propriedade de permeabilidade de água na argamassa de revestimento, baseado em que todos os traços de argamassas com incorporação de borracha de pneus obtiveram taxas médias de absorção de água maiores que a taxa média de absorção de água da argamassa controle. 
Figura 5: Resultados da relação: tempo x permeabilidade à água.

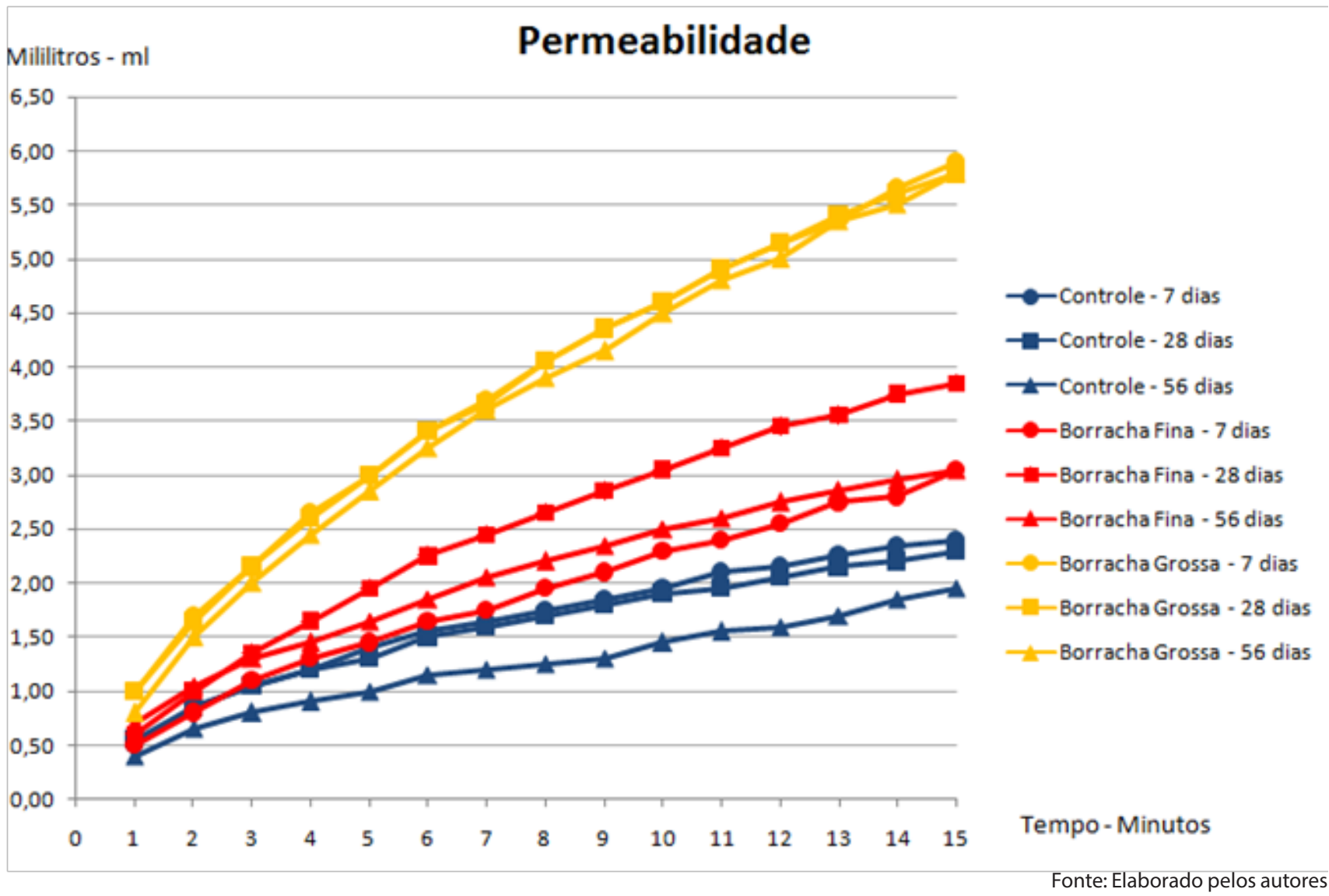

\subsection{Resistência ao impacto de corpo duro}

A resistência ao impacto de corpo duro esta relacionada com a capacidade que a argamassa de revestimento tem, de oferecer segurança no uso e garantir seu desempenho após o choque, em termos físicos e visuais durante o seu tempo de vida útil, sendo expressa em termos de energia de impacto (em Joule). Na sequência serão apresentados os resultados dos ensaios de resistência ao impacto de corpo duro através da Tabela 4.

De acordo com os resultados da Tabela 4, verifica-se que foi necessário um maior número de impactos, e consequentemente maior energia, para a observação do aumento das fissuras iniciais das argamassas produzidas com borracha de pneus, em relação ao aumento da fissura inicial da Tabela 4: Resultados da resistência ao impacto de corpo duro. argamassa controle. Porém, nas argamassas com borracha de pneus ocorreu o surgimento das fissuras iniciais com um menor número de golpes do que na argamassa controle.

Analisando sob outro ponto de vista, destaca-se ainda que ao examinar a evolução da fissura inicial até a espessura final observada, puderam-se constatar em todos os casos as seguintes ocorrências:

- para a argamassa controle à aplicação de um único impacto subsequente à fissura inicial determinou o aumento da abertura desta à no mínimo $1 \mathrm{~mm}$, e resultou ainda no seccionamento total da argamassa de revestimento e do painel de alvenaria;

- para as argamassas produzidas com de borracha de pneus à aplicação de alguns impactos subsequentes à

\begin{tabular}{|c|c|c|c|c|c|c|c|c|c|c|}
\hline \multicolumn{11}{|c|}{ Determinação da Resistência ao Impacto nos Painéis } \\
\hline \multirow[b]{2}{*}{ Traço } & \multirow[b]{2}{*}{$\begin{array}{l}\text { Idade } \\
\text { (dias) }\end{array}$} & \multicolumn{4}{|c|}{$1^{2}$ Fissura Observada } & \multicolumn{4}{|c|}{ Ültima Fissura Observada } & \multirow[b]{2}{*}{ Observaçōes } \\
\hline & & $\underset{\text { Impactos }}{\mathrm{N}^{\circ}}$ & $\begin{array}{c}\text { Altura de } \\
\text { Queda } \\
\text { (m) }\end{array}$ & $\begin{array}{l}\text { Resistência } \\
\text { ao Impacto } \\
\text { (J) }\end{array}$ & $\begin{array}{c}\text { Espessura } \\
\text { (mm) }\end{array}$ & $\begin{array}{c}\mathbf{N}^{\circ} \\
\text { Impactos }\end{array}$ & $\begin{array}{c}\text { Altura de } \\
\text { Queda } \\
\text { (m) }\end{array}$ & $\begin{array}{c}\Sigma \text { de } \\
\text { Energia } \\
\text { (J) }\end{array}$ & $\begin{array}{l}\text { Espessura } \\
\text { (mm) }\end{array}$ & \\
\hline Controle & 28 & 14 & 1,50 & 116,62 & 0,10 & 15 & 1,60 & 132,30 & 1,00 & Seccionamento Total \\
\hline Borracha Fina & 28 & 11 & 1,20 & 75,46 & 0,10 & 15 & 1,60 & 132,30 & 1,00 & Seccionamento Parcial \\
\hline Borracha Grossa & 28 & 13 & 1,40 & 101,92 & 0,10 & 19 & 2.00 & 204.82 & 1.00 & Seccionamento Parcial \\
\hline
\end{tabular}


primeira fissura resultou tão somente no aumento da abertura das fissuras à no máximo 1mm, além disso, acarretou no seccionamento parcial das argamassas e dos painéis de alvenaria.

Percebeu-se, depois da realização do ensaio na argamassa com borracha grossa, que alguns dos resíduos de borracha de pneus (com formato alongado - tipo fibra) estavam ainda contribuindo para a integridade física das argamassas. Uma interação semelhante a esta foi observada anteriormente por RAGHVAN et al. (1998), que ao ensaiarem corpos de prova de argamassa produzidas com borracha de pneus à flexão relataram que é possível verificar que após a falha da matriz da argamassa os pedaços de borracha suportam a fissuração e previnem a ruptura total do corpo de prova.

Para DHIR et al. (2003), que realizaram ensaio de impacto de corpo duro no concreto utilizando duas granulometrias diferentes, concluíram que a dimensão das partículas de borracha de pneus influenciou nos seus resultados, pois os melhores resultados foram obtidos quando se trabalhou com borracha de dimensões maiores.

De maneira geral, as argamassas de revestimento contendo borracha de pneus suportaram maior absorção de energia antes do aumento das fissuras iniciais até o máximo de abertura de $1 \mathrm{~mm}$, se comparados com a argamassa controle. Além disso, a argamassa com a granulometria grossa apresentou a maior capacidade de absorção de energia (tenacidade), quando comparada com a argamassa controle.

\subsection{Susceptibilidade à fendilhação}

Os resultados mostraram que, ao fim de 56 dias, nenhum tipo de argamassa apresentava fissuração alguma. Assim, conclui-se que as argamassas produzidas com a incorporação de 10\% (em volume) de borracha de pneus não apresentam susceptibilidade à fendilhação.

PEDRO (2011) que trabalhou com argamassas incorporadas de $5 \%, 10 \%$ e $15 \%$ de borracha de pneus observou que ao final de 3 meses, nenhum tipo de argamassa produzida em seus ensaios apresentava qualquer fissuração. Sendo assim, o citado autor concluiu que as argamassas produzidas para as diferentes taxas de substituição de agregados naturais por agregados de borracha de pneus usados não apresentam susceptibilidade à fendilhação.

\section{CENÁRIOS DE REDUÇÃO DA BORRACHA DE PNEUS}

Diante dos resultados apresentados, tendo em vista a aceitação desta argamassa de revestimento com incorporação de borracha de pneus, no percentual estudado de $10 \%$ em volume, poderíamos realizar uma simulação de estimativa do consumo de borracha proveniente do processo da recauchutagem de pneus:

- 10\% de borracha de pneus incorporado na argamassa de revestimento: será necessário aproximadamente $1 \mathrm{~kg}$ de borracha de pneus na produção de $1 \mathrm{~m}^{2}$ de argamassa de revestimento. Com a incorporação de 10\% (em volume), teríamos um consumo de borracha de aproximadamente $225 \mathrm{~kg}$ em uma habitação social de $40 \mathrm{~m}^{2}$, e considerando que a habitação fosse reproduzida 200 vezes em um conjunto habitacional, teríamos um consumo em torno de $245.000 \mathrm{~kg}$ de borracha de pneus de recauchutagem na produção das 200 casas.

Estes números indicam uma redução significativa de resíduos de borracha da recauchutagem de pneus no cenário de disposição final.

Portanto, conforme a estimativa apresentada, a utilização de borracha de pneus na argamassa de revestimento contribui na redução desse tipo de resíduo que é gerado, além de ser mais um material alternativo para a construção civil.

\section{CONCLUSÕES}

Nos ensaios de permeabilidade à água, observou-se que com o aumento das granulometrias da borracha de pneus as argamassas de revestimento tiveram tendência de aspecto mais rugoso e consequentemente mais permeabilidade à água.

Com relação à resistência ao impacto de corpo duro, o comportamento de ruptura das argamassas de revestimento produzidas com borracha de pneus foi diferente da argamassa controle, pois foram observadas significativas alterações que demonstraram a efetiva participação física da borracha de pneus na contenção do seccionamento da argamassa. Porém, não foi possível quantificar tal contribuição, mas é visível o aumento da capacidade de absorção de energia (tenacidade) das argamassas com borracha de pneus. Pode ser constatado que a argamassa com a granulometria de borracha grossa apresentou o melhor resultado de impacto, indicando que as dimensões das partículas de borracha interferem na absorção de energia das argamassas.

Com os resultados de susceptibilidade à fendilhação, obteve-se como conclusão que as argamassas incorporadas com $10 \%$ (em volume) de borracha de pneus de diferentes granulometrias não apresentam fissuras.

Diante dos resultados obtidos, tem-se como indicativo de melhores resultados avaliando todos os ensaios, a granulometria de borracha fina, com o percentual de $10 \%$ em volume de borracha de pneus a ser adicionada na argamassa de revestimento. É possível afirmar, contudo, que é necessário ampliar o conhecimento sobre o 
comportamento de argamassas produzidas com borracha de pneus. Faz-se necessário que mais pesquisas venham ser desenvolvidas com o intuito de enriquecer os conhecimentos sobre este material alternativo.

\section{AGRADECIMENTO}

FAPESP - Fundação de Amparo à Pesquisa do Estado de São Paulo, pela concessão da bolsa a autora.

\section{REFERÊNCIAS}

PEDRO, D. A. G. Desempenho de argamassas fabricadas com incorporação de materiais finos provenientes da trituração de pneus. 2011, 155 f. Dissertação (Mestrado) - Instituto Superior Técnico da Universidade Técnica de Lisboa, Lisboa, 2011.

TRIGO, A. P. M.; MARQUES, A. C.; AKASAKI, J. L.; MARINHO, J. R. D. Argamassa com adição de resíduos de borracha submetida à elevada temperatura. In: Congresso Brasileiro do Concreto, 47, 2005, Olinda. Anais... Olinda: IBRACON, p. 55-63.

RAGHVAN, D.; HUYNH, H.; FERRARIS, C. F. Workability, mechanical properties, and chemical stability of a recycled tyre rubber-fillet cementations composite. Journal of Materials Science, v. 33, p. 1745-1752, 1998.

ASSOCIAÇÃO BRASILEIRA DE NORMAS TÉCNICAS. NBR NM 23: Cimento Portland e outros materiais em pó Determinação da massa específica. Rio de Janeiro, 2001.

ASSOCIAÇÃO BRASILEIRA DE NORMAS TÉCNICAS. NBR NM 45: Agregados - Determinação da massa unitária e do volume de vazios. Rio de Janeiro, 2006.

ASSOCIAÇÃO BRASILEIRA DE NORMAS TÉCNICAS. NBR NM 52: Agregado miúdo - Determinação de massa específica e massa específica aparente. Rio de Janeiro, 2009.

ASSOCIAÇÃO BRASILEIRA DE NORMAS TÉCNICAS. NBR NM 53: Agregado graúdo - Determinação da massa específica, massa específica aparente e absorção de água. Rio de Janeiro, 2003.

THOMAZ, E. Tecnologia, gerenciamento e qualidade na construção civil. São Paulo: Editora Pini, 2001.

FIORITI, C. F. Pavimentos intertravados de concreto utilizando resíduos de pneus como material alternativo. 2007. 202 f. Tese (Doutorado) - Escola de Engenharia de São Carlos da Universidade de São Paulo, São Carlos, 2007.

ASSOCIAÇÃO BRASILEIRA DE NORMAS TÉCNICAS. NBR 9778: Argamassa e concreto endurecidos Determinação da absorção de água, índice de vazios e massa específica. Rio de Janeiro, 2005.

CENTRE SCIENTIFIQUE ET TECHNIQUE DE LA CONSTRUCTION - CSTC. Hydrofuges de surface: choix et mise em oeuvre. Bruxelles. (Note D'Information Technique - NIT n. 140), 24 p., 1982.

CENTRE SCIENTIFIQUE ET TECHNIQUE DU BÂTIMENT - CSTB. Certification des enduits monocouches d' imperméabilisation: Modalités $d^{\prime}$ essais. Cahiers du Centre Scientifique et Tecchnique du Bâtiment, L.341, C.2669-4, 7p., 1993.

ASSOCIAÇÃO BRASILEIRA DE NORMAS TÉCNICAS. NBR 9454: Determinação da resistência ao impacto de piso cerâmico. Rio de Janeiro, 1986. (norma extinta).

DHIR, R., PAINE, K. EMORONEY, R. Recycling of used tyres in concrete. Concrete, London, v. 37, n॰ 9, p.47-48, 2003. 